$\$$ Research Square

\title{
Longitudinal Study of Boxing Therapy in Parkinson's Disease, Including Adverse Impacts of the COVID-19 Lockdown
}

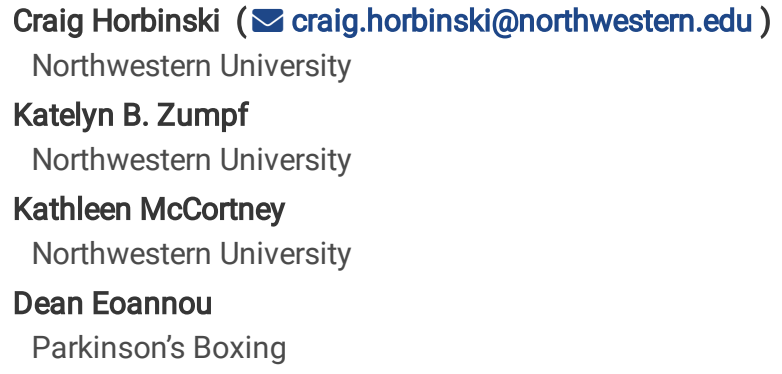

\section{Research Article}

Keywords: Boxing therapy, Parkinson Disease, COVID-19

Posted Date: April 7th, 2021

DOI: https://doi.org/10.21203/rs.3.rs-355283/v1

License: (;) This work is licensed under a Creative Commons Attribution 4.0 International License. Read Full License 


\section{Abstract \\ Background:}

Parkinson's Disease (PD) is a highly prevalent neurodegenerative disease whose incidence is increasing with an aging population. One of the most serious manifestations of PD is gait instability, leading to falls and subsequent complications that can be debilitating, even fatal. Boxing therapy (BT) uses gait and balance exercises to improve ambulation in people with PD, though its efficacy has not yet been fully proven.

\section{Methods:}

In the current longitudinal observational study, 98 participants with idiopathic PD underwent twice-weekly BT sessions. Primary outcome was self-reported falls per month; secondary outcomes were quantitative and semi-quantitative gait and balance performance evaluations. Statistical methods included segmented generalized estimating equation with an independent correlation structure, binomial distribution, and log link.

\section{Results:}

The average number of self-reported falls per month per participant decreased by $87 \%$, from $0.86 \pm 3.58$ prior to BT, to $0.11 \pm 0.26$ during BT. During the lockdown imposed by COVID-19, this increased to $0.26 \pm 0.48$ falls per month. Females and those $>65$ years old reported the greatest increase in falls during the lockdown period. Post-lockdown resumption of BT resulted in another decline in falls, to $0.14 \pm 0.33$. Quantitative performance metrics, including standing from a seated position and standing on one leg, largely mirrored the pattern of falls preand post-lockdown.

\section{Conclusions:}

BT may be an effective option for many PD patients.

\section{Background}

Parkinson's Disease (PD) is among the most common neurodegenerative conditions worldwide, with an estimated lifetime risk of $2 \%$ and a prevalence of 1-2 per 1000 people over 65 years old [1]. Although not directly lethal, the motor disturbances and gait imbalance caused by PD greatly increase the risk of falls, which in turn increases risk of head trauma, fractures, and subsequent immobility. That, in turn, increases risk of thrombosis and infections; indeed, the most common cause of death in PD patients is pneumonia [2]. Thus, therapeutic approaches designed to reduce the risk of falls can have a great impact on patients with PD.

Boxing therapy (BT) -specifically, key exercises employed by boxers to improve their balance and gait in the ring-is becoming a popular way to mitigate PD-associated motor deficits. Much of what has been published is qualitative in nature, describing overall satisfaction with BT programs by PD participants [3, 4]. However, empiric data supporting BT in PD, especially its ability to reduce the risk of falls, is scarce [5]. Studies that do contain specific, rigorous, quantitative data on BT were based on cohorts of 30 participants or less [6, 7].

In this study, we explored the effects of BT in a cohort of 98 participants with PD, focusing on risk of falls as a primary endpoint. Because longitudinal tracking of BT participants encompassed the COVID-19 pandemic-associated lockdown, the effect of that lockdown, and the associated temporary cessation of BT, on outcomes is also addressed.

\section{Methods}

\section{BT exercises and performance measurements}

On initial evaluation, each participant was screened for details regarding their PD diagnosis, including symptoms, self-reported frequency of falls, other medical conditions and comorbidities, and medications. Each participant was then matched with a trainer, who provided one-on-one assessment and coaching throughout the duration of the program. Twice per week, each participant worked with their trainer on specific boxing-related exercises aimed at improving overall coordination, gait, and balance.

At the beginning of each month, including before the very first session, each participant was asked to estimate how many falls they had experienced the prior month. At that time, each participant was evaluated by their trainer as follows: (i) the number of times a participant could 
stand up from a sitting position on a chair in 15 seconds; (ii) the number of seconds, up to 30 , that a participant could stand on one leg before losing balance.

Participants were also evaluated as to how well they could stand up from the floor, their normal walk, their ability to walk a straight line, their ability to walk backwards, their ability to walk with one foot crossing over in front of the other foot, and heel-toe touching. For each of those parameters, a semi-quantitative scoring system was as follows:

1. participant was unable to perform the activity at all, even with help

2. participant required assistance 3 or more times, or stepped off the line 3 or more times in the case of heel-toe, crossovers, or walking a straight line

3. participant required no assistance

\section{Statistics}

Descriptive statistics were used to summarize participant characteristics. Frequency and percent were recorded for all categorical variables and mean, standard deviation, median, inter-quartile range, and range for all numeric variables. To evaluate the change in risk of falling over the course of BT, the stay-at-home lockdown due to the COVID-19 pandemic, and return-to-BT periods, we performed a segmented Generalized Estimating Equation (GEE) with an independent correlation structure, binomial distribution, and log link. Models using different correlation structures (unstructured, exchangeable, auto-correlation, and m-dependent) and distributions (log-binomial or negative-binomial) were compared using QIC. We included a random effect for clients to account for repeat measurements. Fixed effects were specified according to Wagner et al. [8] with two change points. These include: (1) the month from baseline or BT onset; (2) a binary indicator for BT session due to the COVID-19 pandemic (coded 1 while BT was paused due to the pandemic and 0 otherwise); (3) the month since BT cessation (coded 0 if during the boxing or return period); (4) a binary indicator for return to BT (coded 1 after client returns to boxing after COVID-19 onset and 0 otherwise); (5) month since client returned to BT (coded 0 if during BT or BT cessation period). Additionally, we controlled for the average number of falls per month clients reported prior to BT. To determine whether the effect of BT was different between males and females, we repeated the analysis above within male and female sub-groups. Subgroup analyses were also performed on those $<65,65-75$, and $>75$ years of age.

To evaluate whether other performance measures, such as the number of times participants could stand upright from a chair or seconds participants were able to stand on their right and left leg, changed over time with the addition of BT, we again used segmented GEE models. A Poisson distribution with an autocorrelated correlation structure was used to model the number of times participants were able to stand from a chair. Analysis of the time participants were able to stand on their right and left leg was done in 2-fold: first, modelling the risk of standing for 30 seconds using a binomial distribution and log link, then modelling the number of seconds stood in those who could only stand less than 30 seconds using a Poisson distribution. In both cases, an independent correlation structure was assumed. Fixed effects included months from BT onset, and indicator for returning to BT after the COVID-19 lockdown, and the months since the client returned to BT.

No participants had performance measurements collected before BT began, nor during the COVID-19 lockdown. Few participants had performance measurements collected while BT was paused due to COVID-19, which would have otherwise served as a control state for participants. Thus, analysis was limited to data collected during BT before the lockdown and when participants returned to BT after the lockdown.

Analyses were performed using R (R Core Team, Version 2.0.3, 2020) and SAS software (Copyright (c) 2016 by SAS Institute Inc., Cary, NC, USA) and assumed a two-sided, $5 \%$ level of significance.

\section{Results}

\section{Descriptive Statistics}

Ninety-eight participants with idiopathic PD were enrolled in the study, with an average age of 70.6 years (Table 1). Twenty-two percent (22/98) of participants were female. Based on interviews conducted at the beginning of BT, participants self-reported an average of $0.86 \pm 3.58$ falls per month at baseline. 
Table 1

Description of study participants.

\begin{tabular}{|c|c|}
\hline & $\begin{array}{l}\text { all } \\
(n=98)\end{array}$ \\
\hline \multicolumn{2}{|l|}{ age } \\
\hline mean (SD) & 70.6 (7.98) \\
\hline median (q1-q3) & $71.0(66.0-77.0)$ \\
\hline [min, max] & {$[41.0,89.0]$} \\
\hline \multicolumn{2}{|l|}{ age category } \\
\hline$<65$ & $20(20.4 \%)$ \\
\hline $65-75$ & $48(49.0 \%)$ \\
\hline$>75$ & 30 (30.6\%) \\
\hline \multicolumn{2}{|l|}{ sex } \\
\hline male & $76(77.6 \%)$ \\
\hline female & $22(22.4 \%)$ \\
\hline \multicolumn{2}{|c|}{ pre-BT self-reported average number of falls per month } \\
\hline mean (SD) & $0.861(3.58)$ \\
\hline median (q1-q3) & $0.0417(0-0.167)$ \\
\hline$[\min , \max ]$ & {$[0,30.0]$} \\
\hline
\end{tabular}

The average follow-up interval during BT was 16.0 months (Table 2). During BT, the mean average number of self-reported falls per month per participant decreased from $0.86 \pm 3.58$ at baseline to $0.11 \pm 0.26$ during BT. During the COVID-19 lockdown, when BT was paused for an average of 3 months, falls increased from $0.11 \pm 0.26$ falls per month during the initial BT interval to $0.26 \pm 0.48$ falls per month. Once BT was resumed post-lockdown, participants reported another decline in falls, from $0.26 \pm 0.48$ falls per month to $0.14 \pm 0.33$. Likewise, the average proportion of months in which at least one fall was reported increased from $8 \pm 0.15 \%$ during the initial phase of BT, to $12 \pm 0.18 \%$ during the COVID-19 period, then decreased slightly to $10 \pm 0.21 \%$ after participants returned to boxing. (Of note, 17 of the original 98 participants did not resume BT after the lockdown.) 
Table 2

Summary of falls per study interval.

\begin{tabular}{|llll|}
\hline \multicolumn{2}{|c|}{$\begin{array}{l}\text { pre-lockdown BT } \\
(\mathbf{n = 9 8})\end{array}$} & $\begin{array}{l}\text { covid-19 lockdown interval } \\
(\mathbf{n o ~ B T}) \\
(\mathbf{n = 9 8})\end{array}$ & $\begin{array}{l}\text { post-lockdown BT } \\
(\mathbf{n}=\mathbf{8 1})\end{array}$ \\
\hline months of follow-up & & $3.22(0.697)$ & $4.73(1.00)$ \\
\hline mean (SD) & $16.0(12.2)$ & $5.00(3.00-3.00)$ & $5.00(5.00-5.00)$ \\
\hline median (q1-q3) & $11.0(8.25-21.8)$ & {$[1.00,10.0]$} \\
\hline [min, max] & {$[2.00,50.0]$} & {$[3.00,7.00]$} & $0.143(0.330)$ \\
\hline average number of falls per month & & & $0(0-0.200)$ \\
\hline mean (SD) & $0.109(0.261)$ & $0.255(0.481)$ & {$[0,1.50]$} \\
\hline median (q1-q3) & $0(0-0.106)$ & $0(0-0.333)$ & \\
\hline [min, max] & {$[0,1.60]$} & {$[0,2.00]$} & $0.102(0.207)$ \\
\hline proportion of months with at least 1 fall & & & $0(0-0.200)$ \\
\hline mean (SD) & $0.0764(0.151)$ & $0.117(0.182)$ & {$[0,1.00]$} \\
\hline median (q1-q3) & $0(0-0.0890)$ & $0(0-0.333)$ & \\
\hline [min, max] & {$[0,0.875]$} & {$[0,0.800]$} & \\
\hline
\end{tabular}

Seventeen of the original 98 participants did not resume BT after the lockdown.

\section{Modeling Falls}

Over 2,094 aggregate months of data, 175 falls were self-reported ( $8 \%$ of all participant-months). After adjusting for average self-reported number of falls per month prior to $\mathrm{BT}$, there did not appear to be a significant change in relative risk of falling over time during the initial $\mathrm{BT}$ interval (RR: $1.01,95 \% \mathrm{Cl}(0.99,1.03), P=0.3050)$ (Table 3, Fig. 1, and Supplemental Table 1). From the beginning of the lockdown to the resumption of $\mathrm{BT}$, the relative risk of falling increased by $51 \%$ each month (RRL 1.5058,95\% $\mathrm{Cl}(1.26,1.79), P<0001)$. Once $\mathrm{BT}$ was resumed after the lockdown, the risk of falling decreased $20 \%$ each month (RR: $0.7992,95 \% \mathrm{Cl}(0.68,0.95), P=0.0093)$; this was a $21 \%(\mathrm{RR}: 0.79,95 \% \mathrm{Cl}$ $(0.67,0.94), P=0.0071)$ decrease in change in relative risk per month (i.e., slope) from the initial BT period and a $47 \%(\mathrm{RR}: 0.53,95 \% \mathrm{Cl}(0.41$, $0.68), P<0.001)$ decrease from the COVID-19 lockdown interval.

Table 3

Modelling risk of falling at least once, contrast estimates.

\begin{tabular}{|lllll|}
\hline time period & \multicolumn{4}{l|}{ change in risk over time } \\
\cline { 2 - 5 } & estimate & $95 \%$ confidence interval & P \\
\hline BT & 1.0115 & 0.9897 & 1.0337 & 0.3050 \\
\hline lockdown & 1.5058 & 1.2614 & 1.7975 & $<0.0001$ \\
\hline return & 0.7992 & 0.6750 & 0.9462 & 0.0093 \\
\hline lockdown vs BT & 1.4887 & 1.2434 & 1.7825 & $<0.0001$ \\
\hline return vs lockdown & 0.5307 & 0.4148 & 0.6790 & $<0.0001$ \\
\hline
\end{tabular}

Modeling was based on the number of months in which at least one fall occurred. Return = post-lockdown resumption of BT.

Similar results as described above were seen when excluding 49 participants who never reported any falls, at any time during the study period (Supplemental Tables 2 and 3).

\section{Sex as a Variable in Falls Reduced by BT}

During the monitoring period, $10 \%$ (44/404) of female visits and 7\% (131/1690) of male visits recorded a fall. In both males and females, there was no change in falls during the initial BT period or after returning post-lockdown. Similarly, females reported a greater increase in risk of 
falling per month during the COVID period: $84 \%$ increase per month in females (RR: $1.84,95 \% \mathrm{Cl}(1.05,3.24), P=0.0318)$ vs. $49 \%$ increase per month in males (RR: $1.49,95 \% \mathrm{Cl}(1.23,1.81), P<0.0001)$ (Table 4). After resuming BT, females experienced a $24 \%$ decrease in risk of falling per month (RR: $0.76,95 \% \mathrm{Cl}(0.57,0.996), P=0.0471)$, whereas the decrease in males was not statistically significant (RR: $0.82,95 \% \mathrm{Cl}(0.66$, 1.02), $P=0.0718)$.

Table 4

Sex as a variable in falls during BT, based on number of months in which at least one fall occurred.

\begin{tabular}{|c|c|c|c|c|c|c|c|c|}
\hline \multirow{4}{*}{$\begin{array}{l}\text { interval } \\
\text { BT }\end{array}$} & \multicolumn{8}{|c|}{ change in risk over time } \\
\hline & \multicolumn{4}{|c|}{ females ( $n=22)$} & \multicolumn{4}{|c|}{ males $(n=76)$} \\
\hline & \multirow{2}{*}{$\begin{array}{l}\text { estimate } \\
1.0224\end{array}$} & \multicolumn{2}{|c|}{$95 \%$ confidence interval } & \multirow{2}{*}{$\begin{array}{l}P \\
0.2533\end{array}$} & \multirow{2}{*}{$\begin{array}{l}\text { estimate } \\
1.0103\end{array}$} & \multicolumn{2}{|c|}{$95 \%$ confidence interval } & \multirow{2}{*}{$\begin{array}{l}P \\
0.4375\end{array}$} \\
\hline & & 0.9842 & 1.0621 & & & 0.9846 & 1.0366 & \\
\hline lockdown & 1.8493 & 1.0549 & 3.2418 & 0.0318 & 1.4930 & 1.2311 & 1.8105 & $<0.0001$ \\
\hline retum & 0.7559 & 0.5735 & 0.9964 & 0.0471 & 0.8202 & 0.6611 & 1.0177 & 0.0718 \\
\hline lockdown vs BT & 1.8087 & 1.0532 & 3.1060 & 0.0317 & 1.4778 & 1.2147 & 1.7978 & $<0.0001$ \\
\hline retum vs lockdown & 0.4088 & 0.2325 & 0.7186 & 0.0019 & 0.5494 & 0.4082 & 0.7394 & $<0.0001$ \\
\hline
\end{tabular}

Return = post-lockdown resumption of BT.

\section{Age as a Variable in Falls Reduced by BT}

To assess the effect of age in BT and PD-associated falls, we stratified the cohort into participants $<65$ years old ( $n=20,20 \%), 65-75$ years old $(n=48,49 \%)$, and $>75$ years old $(n=30,31 \%)$ at the beginning of BT. Among those $<65$ years old, $5 \%$ of all observations $(22 / 445)$ reported a fall. This increased to $8 \%(88 / 1135)$ in those $65-75$ years of age, and $9 \%(65 / 689)$ in those $>75$ years of age. Over the initial course of BT, risk of falls increased by $2 \%$ each month for those < 65 years old (RR: $1.02,95 \%$ Cl: $(1.01,1.04), P=0.0048)$ and $>75$ years old (RR: $1.02,95 \%$ Cl: $(1.00,1.05), P=0.0405)$, but no significant change was observed in participants between $65-75$ years (RR: $1.02,95 \% \mathrm{Cl}$ : $(0.98,1.05), P=$ 0.2861 ) (Table 5). During the COVID-19 lockdown, those > 65 years old experienced the greatest increase in the number of falls over time: $85 \%$ greater per month in those $65-75$ years of age (RR: $1.85,95 \% \mathrm{Cl}$ : $(1.32,2.59), P=0.0003)$ and $59 \%$ greater in those greater than 75 years of age (RR: $1.63,95 \% \mathrm{Cl}:(1.24,2.15), P=0.0005)$. There was no significant change in risk of falling in those $<65$ years of age during the lockdown (RR: $1.74,95 \% \mathrm{Cl}:(0.92,3.28), P=0.0903)$. As a result, only those $65-75$ of age saw a significant reduction in risk of falling per month once BT was re-initiated after lockdown (RR: $0.76,95 \% \mathrm{Cl}$ : $(0.61,0.93), P=0.0085)$.

Table 5

Age as a variable in falls during BT, based on number of months in which at least one fall occurred.

\begin{tabular}{|c|c|c|c|c|c|c|c|c|c|c|c|c|}
\hline \multirow[t]{3}{*}{ interval } & \multicolumn{12}{|c|}{ change in risk over time } \\
\hline & \multicolumn{4}{|l|}{$<65$ years } & \multicolumn{4}{|c|}{$65-75$ years } & \multicolumn{4}{|l|}{$>75$ years } \\
\hline & \multirow{2}{*}{$\begin{array}{l}\text { estimate } \\
1.0205\end{array}$} & \multicolumn{2}{|c|}{$\begin{array}{l}95 \% \text { confidence } \\
\text { interval }\end{array}$} & \multirow{2}{*}{$\begin{array}{l}\mathbf{P} \\
0.0048\end{array}$} & \multirow{2}{*}{$\begin{array}{l}\text { estimate } \\
1.0186\end{array}$} & \multicolumn{2}{|c|}{$\begin{array}{l}95 \% \text { confidence } \\
\text { interval }\end{array}$} & \multirow{2}{*}{$\begin{array}{l}\mathbf{P} \\
0.2861\end{array}$} & \multirow{2}{*}{$\begin{array}{l}\text { estimate } \\
1.0231\end{array}$} & \multicolumn{2}{|c|}{$\begin{array}{l}95 \% \text { confidence } \\
\text { interval }\end{array}$} & \multirow{2}{*}{$\begin{array}{l}\mathbf{P} \\
0.0405\end{array}$} \\
\hline BT & & 1.0062 & 1.0351 & & & 0.9847 & 1.0536 & & & 1.0010 & 1.0457 & \\
\hline lockdown & 1.7353 & 0.9170 & 3.2837 & 0.0903 & 1.8494 & 1.3205 & 2.5903 & 0.0003 & 1.6311 & 1.2402 & 2.1452 & 0.0005 \\
\hline return & 0.6626 & 0.4380 & 1.0021 & 0.0512 & 0.7553 & 0.6128 & 0.9309 & 0.0085 & 0.9374 & 0.6796 & 1.2929 & 0.6934 \\
\hline $\begin{array}{l}\text { lockdown } \\
\text { vs BT }\end{array}$ & 1.7004 & 0.8988 & 3.2166 & 0.1027 & 1.8157 & 1.2865 & 2.5626 & 0.0007 & 1.5942 & 1.2111 & 2.0986 & 0.0000 \\
\hline $\begin{array}{l}\text { return vs } \\
\text { lockdown }\end{array}$ & 0.3818 & 0.1901 & 0.7670 & 0.0068 & 0.4084 & 0.2713 & 0.6146 & $\begin{array}{l}< \\
0.0001\end{array}$ & 0.5747 & 0.3747 & 0.8813 & 0.0111 \\
\hline
\end{tabular}

Return = post-lockdown resumption of BT.

\section{Performance Metrics}

Other performance measures, such as the number of times participants were able to stand from a chair in 15 seconds, stand on each leg for 30 seconds, stand from the floor, walk normally, heel-toe touch, crossover, walk backwards, and, were collected for an average $16 \pm 12$ months of BT before the lockdown and $5 \pm 1$ months after resumption of BT. All metrics except standing from a chair and on each leg were semiquantitative, as described in the Methods. The median number of times participants were able to stand from a chair in 15 seconds was 7 
times during BT and 8 times after the lockdown when BT resumed (Table 6). During the initial BT interval, participants were able to stand on their right and left leg for $15.7 \pm 11.3$ and $14.7 \pm 10.7$ seconds, respectively. During the post-lockdown interval, the average duration increased to $17.1 \pm 11.4$ and $16.2 \pm 10.8$ seconds on the right and left leg, respectively. 
Table 6

Summary of performance metrics.

\begin{tabular}{|c|c|c|c|}
\hline & $\begin{array}{l}\text { BT } \\
(n=98)\end{array}$ & $\begin{array}{l}\text { post-lockdown } \\
(n=81)\end{array}$ & $\begin{array}{l}\text { all } \\
(n=179)\end{array}$ \\
\hline \multicolumn{4}{|c|}{ months of follow-up } \\
\hline mean (SD) & $16.0(12.2)$ & $4.73(1.00)$ & $10.9(10.7)$ \\
\hline median (q1-q3) & $11.0(8.25-21.8)$ & $5.00(5.00-5.00)$ & $5.00(5.00-11.5)$ \\
\hline [min, max] & {$[2.00,50.0]$} & {$[1.00,10.0]$} & {$[1.00,50.0]$} \\
\hline \multicolumn{4}{|c|}{ average number of falls per month } \\
\hline mean (SD) & $0.109(0.261)$ & $0.143(0.330)$ & $0.124(0.294)$ \\
\hline median (q1-q3) & $0(0-0.106)$ & $0(0-0.200)$ & $0(0-0.118)$ \\
\hline [min, max] & {$[0,1.60]$} & {$[0,1.50]$} & {$[0,1.60]$} \\
\hline \multicolumn{4}{|c|}{ average stand from chair } \\
\hline mean (SD) & $7.11(3.47)$ & $8.08(3.97)$ & $7.56(3.73)$ \\
\hline median (q1-q3) & $7.25(5.20-9.29)$ & $7.80(6.23-10.9)$ & $7.55(6.00-9.80)$ \\
\hline$[\min , \max ]$ & {$[0,14.0]$} & {$[0,17.8]$} & {$[0,17.8]$} \\
\hline missing & $11(11.2 \%)$ & $6(7.4 \%)$ & $17(9.5 \%)$ \\
\hline \multicolumn{4}{|c|}{ average stand from floor } \\
\hline mean (SD) & $2.61(0.580)$ & $2.68(0.589)$ & $2.64(0.584)$ \\
\hline median (q1-q3) & $3.00(2.00-3.00)$ & $3.00(2.78-3.00)$ & $3.00(2.00-3.00)$ \\
\hline$[\min , \max ]$ & {$[1.00,3.00]$} & {$[1.00,3.00]$} & {$[1.00,3.00]$} \\
\hline missing & $11(11.2 \%)$ & $6(7.4 \%)$ & $17(9.5 \%)$ \\
\hline \multicolumn{4}{|c|}{ average normal walk } \\
\hline mean (SD) & $2.99(0.107)$ & $2.98(0.135)$ & $2.98(0.121)$ \\
\hline median (q1-q3) & $3.00(3.00-3.00)$ & $3.00(3.00-3.00)$ & $3.00(3.00-3.00)$ \\
\hline [min, max] & {$[2.00,3.00]$} & {$[2.00,3.00]$} & {$[2.00,3.00]$} \\
\hline missing & $11(11.2 \%)$ & $6(7.4 \%)$ & $17(9.5 \%)$ \\
\hline \multicolumn{4}{|c|}{ average heel toe touch } \\
\hline mean (SD) & $2.47(0.565)$ & $2.47(0.574)$ & $2.47(0.568)$ \\
\hline median (q1-q3) & $2.60(2.00-3.00)$ & $2.75(2.00-3.00)$ & $2.63(2.00-3.00)$ \\
\hline [min, max] & {$[1.00,3.00]$} & {$[1.00,3.00]$} & {$[1.00,3.00]$} \\
\hline missing & $11(11.2 \%)$ & $6(7.4 \%)$ & $17(9.5 \%)$ \\
\hline \multicolumn{4}{|c|}{ average crossovers } \\
\hline mean (SD) & $2.41(0.640)$ & $2.49(0.680)$ & $2.45(0.658)$ \\
\hline median (q1-q3) & $2.67(2.00-3.00)$ & $3.00(2.00-3.00)$ & $2.80(2.00-3.00)$ \\
\hline [min, max] & {$[1.00,3.00]$} & {$[1.00,3.00]$} & {$[1.00,3.00]$} \\
\hline missing & $11(11.2 \%)$ & $6(7.4 \%)$ & $17(9.5 \%)$ \\
\hline \multicolumn{4}{|c|}{ average walk straight line } \\
\hline mean (SD) & $2.69(0.510)$ & $2.70(0.486)$ & $2.69(0.498)$ \\
\hline median (q1-q3) & $3.00(2.40-3.00)$ & $3.00(2.60-3.00)$ & $3.00(2.50-3.00)$ \\
\hline
\end{tabular}




\begin{tabular}{|llll|}
\hline & $\begin{array}{l}\text { BT } \\
(\mathbf{n}=98)\end{array}$ & $\begin{array}{l}\text { post-lockdown } \\
(\mathbf{n}=\mathbf{8 1})\end{array}$ & $\begin{array}{l}\text { all } \\
(\mathbf{n}=179)\end{array}$ \\
\hline [min, max] & {$[1.00,3.00]$} & {$[1.00,3.00]$} & {$[1.00,3.00]$} \\
\hline missing & $11(11.2 \%)$ & $6(7.4 \%)$ & $17(9.5 \%)$ \\
\hline average walk backwards & & & \\
\hline mean (SD) & $2.82(0.370)$ & $2.77(0.461)$ & $2.80(0.414)$ \\
\hline median (q1-q3) & $3.00(2.90-3.00)$ & $3.00(2.80-3.00)$ & $3.00(2.80-3.00)$ \\
\hline [min, max] & {$[1.00,3.00]$} & {$[1.00,3.00]$} & {$[1.00,3.00]$} \\
\hline missing & $11(11.2 \%)$ & $6(7.4 \%)$ & $17(9.5 \%)$ \\
\hline average stand on right leg & & & \\
\hline mean (SD) & $15.7(11.3)$ & $17.1(11.4)$ & $16.3(11.3)$ \\
\hline median (q1-q3) & $14.5(4.00-27.1)$ & $15.8(7.20-30.0)$ & $15.4(5.21-29.4)$ \\
\hline [min, max] & {$[0,30.0]$} & {$[0,30.0]$} & {$[0,30.0]$} \\
\hline missing & $11(11.2 \%)$ & $6(7.4 \%)$ & $17(9.5 \%)$ \\
\hline average stand on left leg & & & $17 \%$ \\
\hline mean (SD) & $14.7(10.7)$ & $16.2(10.8)$ & $15.4(10.8)$ \\
\hline median (q1-q3) & $15.0(4.30-26.3)$ & $16.2(6.10-27.3)$ & $15.3(4.85-26.6)$ \\
\hline [min, max] & {$[0,30.0]$} & {$[0,30.0]$} & {$[0,30.0]$} \\
\hline missing & $11(11.2 \%)$ & $6(7.4 \%)$ & $17(9.5 \%)$ \\
\hline
\end{tabular}

$\mathrm{SD}=$ standard deviation .

During the initial pre-lockdown BT period, the number of times participants were able to stand upright from a sitting position in a 15-second interval significantly increased over time (IRR: $1.01,95 \% \mathrm{Cl}(1.00,1.01), P=0.0193)$ (Fig. 2). Likewise, after participants returned to BT postlockdown, there was another significant improvement each month (IRR: 1.02, 95\% Cl: $(1.01,1.04), P=0.0014)$.

Regarding standing on one leg, of the 1,955 tests performed, $12 \%(n=236)$ resulted in participants able to stand on their right leg for the full 30 seconds and $10 \%(n=198)$ resulted in participants able to stand on their left leg for the full 30 seconds. There was no change in the odds of being able to stand on either leg over time, whether before the COVID-19 lockdown (Right leg RR: $1.01,95 \% \mathrm{Cl}(0.99,1.03), P=0.3544$; Left leg OR: $1.01,95 \% \mathrm{Cl}:(0.98,1.03), P=0.5763)$ or after (Right leg RR: $1.02,95 \% \mathrm{Cl}(0.96,1.08), P=0.5354$; Left leg OR: $1.03,95 \% \mathrm{Cl}:(0.96,1.10), P=$ 0.4301). Of those that stood for less than 30 seconds, there was not a significant change in number of seconds standing over time on either leg before the lockdown (Right leg IRR: 1.00, $95 \% \mathrm{Cl}(0.99,1.01), P=0.9733$; Left leg IRR: $1.00,95 \% \mathrm{Cl}$ : $(0.99,1.01), P=0.8169)$ (Fig. 2). However, after returning to BT after the lockdown, the average number of seconds standing on the right leg increased by $7 \%$ each month (IRR: $1.07,95 \% \mathrm{Cl}:(1.00,1.13), P=0.0370)$. Similarly, the number of seconds standing on the left leg increased by $5 \%$ each month following the lockdown (IRR: $1.05,95 \% \mathrm{Cl}: 1.00,1.10), P=0.0378)$.

Across both periods, the median semi-quantitative score that participants were able to stand from the floor, walk normally, heel toe touch, walk straight, or walk backwards was approximately $3 / 3$ (Table 6). Because there was insufficient variance in those semi-quantitatively-scored metrics, no further analysis of those metrics was done.

\section{Discussion}

Given the aging populations of the developed world, neurodegenerative conditions like PD are becoming more and more common. PD in particular is a problem of chronic risk management, especially reducing the risk of falls, since those falls often result in secondary trauma that is costly to manage, reduces quality-of-life, and increases mortality. Multiple studies have suggested that a variety of physical therapies and exercises can not only slow the rate at which the risk of falls increases in PD patients over time, but may also allow PD patients to regain some of what had been lost prior to initiation of therapy. For example, one meta-analysis suggested that many different approaches, including dancing, hydrotherapy, and robotic gait training, were very effective in PD patients, whereas the evidence for other therapies, like aerobics, 
Nordic walking, and BT, was less conclusive [9]. This is due, in large part, to the relative scarcity of studies that focus on a specific, rather unconventional therapeutic modality like BT $[6,7]$. However, our data, in the largest cohort of its kind to date, suggest that BT may have value in improving gait stability and reducing the risk of falls in PD patients.

The COVID-19 pandemic has had a profound, deleterious, and long-lasting effect on populations worldwide. Even beyond those directly impaired or killed by the virus, measures that were implemented in an effort to slow the spread of disease, including the lockdown imposed by New York State from March-April 2020, have had severe economic and psychological repercussions. One of them is the delay or outright cancellation of health maintenance measures, such as well-visits and cancer screenings, that are critical for early prevention and/or detection of diseases that otherwise can quickly become unmanageable. The current data suggest this also holds true for interventions meant to reduce the impact of PD. In the current study, prior to the lockdown, the rate of self-reported falls had decreased by $87 \%$, from 0.86 per month prior to initiation of BT down to 0.11 during BT (Table 1 and Table 2). But in that two-month lockdown, the rate of falls rapidly increased to more than double what had been observed during BT. Falls then declined again once BT was re-established, and eventually reached nearly the same level as before the lockdown. However, the rate at which improvements were regained after the lockdown was slower than the rate at which they were lost during the lockdown (Table 3). This is not surprising, and comports with other research on inactivity and muscle loss, including the deconditioning that happened during the COVID-19 pandemic [10]. In our cohort, the main risk factors for more rapid and severe increase in falls during BT cessation were female sex and participant age > 65 years old (Table 4 and Table 5). In a prior study of exercise in PD, younger age and male sex were associated with better response to exercise [11]. Our current data comport with this, but also suggest that females can also reduce their risk of falls faster once BT is resumed.

Strengths of this observational study are its prospective nature and the relatively large cohort. One weakness is that the primary outcome, falls, relied on self-reporting, without any monitoring devices designed to record them. However, the quantitative performance metrics observed by a trainer, including standing from a chair and standing on one leg, largely matched the general patterns of what was reported for falls (Fig. 2). Another weakness is that this was not a randomized trial that compared BT to other PD therapies, or to a separate non-exercise control group. However, the COVID-19 lockdown inadvertently provided a unique opportunity to explore the time-dependent effect of BT cessation and resumption in the same cohort of participants. Furthermore, the statistical methods employed tracked each individual patient's change over time, thereby correcting for other potential confounding variables.

\section{Conclusions}

In sum, these data suggest that BT may reduce the risk of falls in PD patients. While other therapies also certainly have value, their ultimate utility depends greatly on the motivation and interest of the participant. BT might have a unique appeal because of its perceived novelty and association with a sport that has a very long history across numerous cultures.

\section{Declarations}

\section{Ethics approval and consent to participate}

This study was performed in accordance with a protocol approved by the Institutional Review Board of Northwestern University (protocol \#STU00213727), in which informed consent by the participants was deemed unnecessary. All patient data was completely de-identified prior to analysis.

\section{Consent for publication}

Not applicable

\section{Availability of data and materials}

The deidentified datasets used and/or analyzed during the current study are available from the corresponding author on request.

\section{Competing interests}

$\mathrm{DE}$ is the proprietor of the $\mathrm{BT}$ clinic from which this data was obtained and analyzed. $\mathrm{CH}, \mathrm{KBZ}$, and $\mathrm{KM}$ have no financial stake whatsoever in the BT clinic, and other than providing the deidentified data and a description of the clinic for this manuscript, DE had no input in these analyses.

Funding

This work was supported in part by R01NS102669 (CH), R01NS117104 (CH), R01NS118039 (CH), and by the Michael J. Fox Foundation. 
$\mathrm{CH}, \mathrm{KBZ}, \mathrm{KM}$, and DE wrote the manuscript. KBZ performed statistical analyses. DE provided the data from his Parkinson's Boxing clinic.

Acknowledgements

The authors thank the trainers at Parkinson's Boxing for working with the participants and recording the data presented and analyzed in this manuscript (Robert Caico, Brad Lojacono, Colleen Eoannou, Griffın Cascio, Jeff Quinn, Jennifer Taggart, Molly Lanham, Paul Hoffman, Roman Figler, Taylor Atkinson, Tyler Kruse, Wendy Casey, Zachary Bauer).

\section{References}

1. Ascherio A, Schwarzschild MA. The epidemiology of Parkinson's disease: risk factors and prevention. Lancet Neurol. 2016;15 12:1257-72; doi: 10.1016/s1474-4422(16)30230-7.

2. Hely MA, Morris JG, Traficante R, Reid WG, O'Sullivan DJ, Williamson PM. The sydney multicentre study of Parkinson's disease: progression and mortality at 10 years. J Neurol Neurosurg Psychiatry. 1999;67 3:300-7.

3. Borrero L, Miller SA, Hoffman E. The meaning of regular participation in vigorous-intensity exercise among men with Parkinson's disease. Disabil Rehabil. 2020:1-7; doi: 10.1080/09638288.2020.1836042.

4. Domingos J, Radder D, Riggare S, Godinho C, Dean J, Graziano M, et al. Implementation of a Community-Based Exercise Program for Parkinson Patients: Using Boxing as an Example. J Parkinsons Dis. 2019;9 3:615 - 23.

5. Morris ME, Ellis TD, Jazayeri D, Heng H, Thomson A, Balasundaram AP, et al. Boxing for Parkinson's Disease: Has Implementation Accelerated Beyond Current Evidence? Front Neurol. 2019;10:1222.

6. Combs SA, Diehl MD, Chrzastowski C, Didrick N, McCoin B, Mox N, et al. Community-based group exercise for persons with Parkinson disease: a randomized controlled trial. NeuroRehabilitation. 2013;32 1:117 - 24; doi: 10.3233/nre-130828.

7. Combs SA, Diehl MD, Staples WH, Conn L, Davis K, Lewis N, et al. Boxing training for patients with Parkinson disease: a case series. Phys Ther. 2011;91 1:132 - 42; doi: 10.2522/ptj.20100142.

8. Wagner AK, Soumerai SB, Zhang F, Ross-Degnan D. Segmented regression analysis of interrupted time series studies in medication use research. J Clin Pharm Ther. 2002;27 4:299-309; doi: 10.1046/j.1365-2710.2002.00430.x.

9. Alves Da Rocha P, McClelland J, Morris ME. Complementary physical therapies for movement disorders in Parkinson's disease: a systematic review. Eur J Phys Rehabil Med. 2015;51 6:693-704.

10. Kirwan R, McCullough D, Butler T, Perez de Heredia F, Davies IG, Stewart C. Sarcopenia during COVID-19 lockdown restrictions: long-term health effects of short-term muscle loss. Geroscience. 2020;42 6:1547-78; doi: 10.1007/s11357-020-00272-3.

11. Combs-Miller SA, Moore ES. Predictors of outcomes in exercisers with Parkinson disease: A two-year longitudinal cohort study. NeuroRehabilitation. 2019;44 3:425 - 32; doi: 10.3233/nre-182641.

\section{Figures}




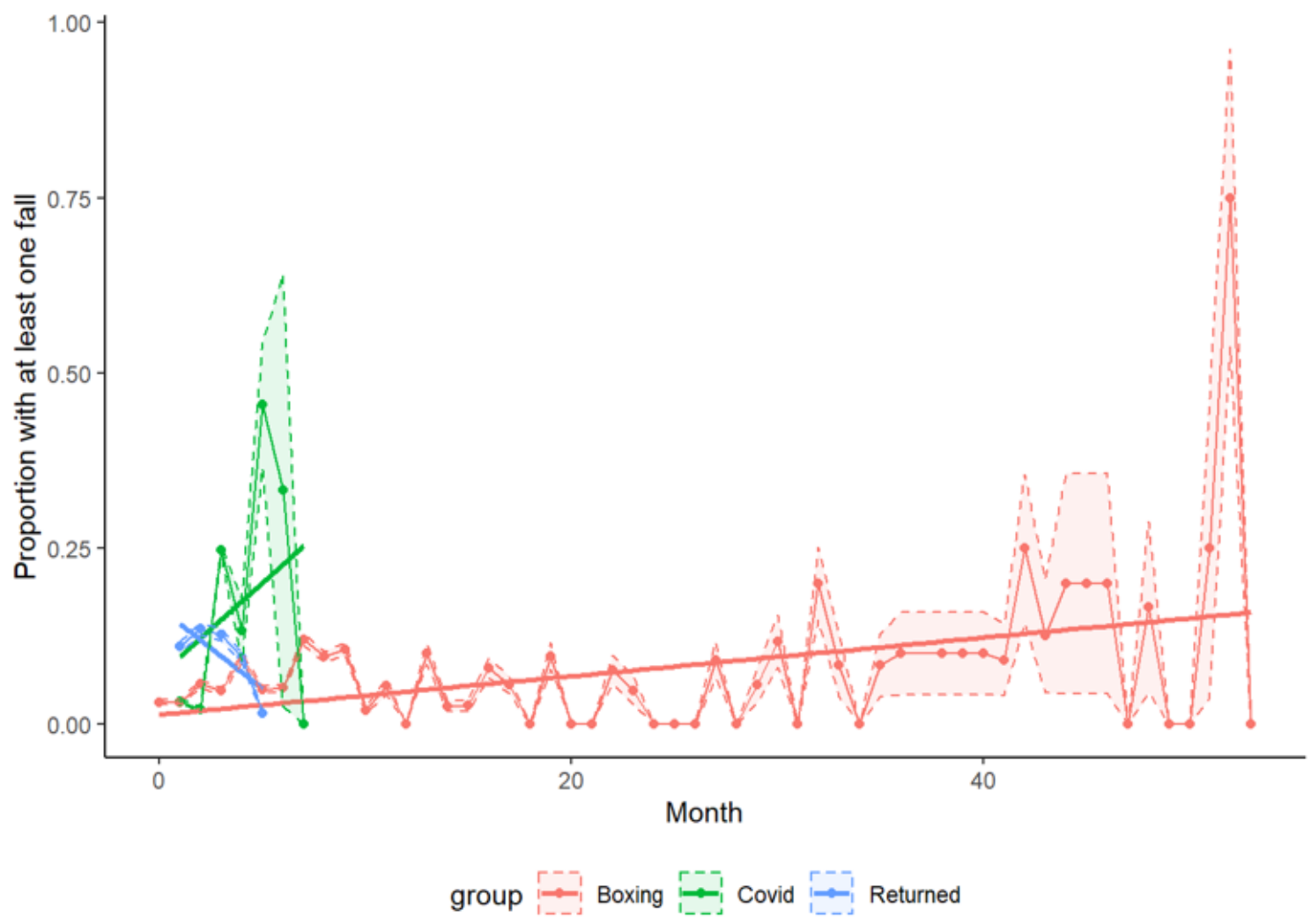

Figure 1

Proportion of participants who report at least one fall. Slope for each interval indicates change in relative risk over time.


$\rightarrow$ BT $\rightarrow$ Post-Lockdown

Figure 2

Distribution of performance measures over time by study interval. Slope for each interval indicates change in relative risk over time.

\section{Supplementary Files}

This is a list of supplementary files associated with this preprint. Click to download. 
- SupplementaryData03232021.docx

Page 13/13 